\title{
Dexamethasone versus betamethasone - a better modality for fetal lung maturity in preterm labour
}

\author{
Aritra Maji, Manisha V Ramani, Vidushi Tiwari \\ Corresponding author: Dr. Manisha V. Ramani, Address: B4-202, Chandragiri BDA Apartments, \\ Doddabanahalli, Bidare Agraha, Bengaluru, Karnataka, India; \\ Email : manisha.ramani21@gmail.com
}

Distributed under Attribution-Non Commercial - Share Alike 4.0 International (CC BY-NC-SA 4.0)

\begin{abstract}
Background: Prematurity constitutes a serious complication in the field of obstetrics worldwide. Various untoward outcomes like respiratory distress syndrome, intra-ventricular haemorrhage, retinopathy of prematurity, necrotising enterocolitis, low birth weight, neonatal mortality are associated with premature birth. The two common antenatal corticosteroids recommended and widely used for accelerating fetal lung maturity in preterm labour are dexamethasone and betamethasone. Objectives: 1) Comparing efficacy of dexamethasone and betamethasone for fetal lung maturity in preterm infants and 2) To study and compare incidence of other prematurity related complications in both groups. Methodology: This prospective comparative study was done in department of Obstetrics and Gynaecology in MVJ Medical College \& Research Hospital involving 100 pregnant lady of gestational age from 28 weeks to 36 weeks +6 days with preterm labour, who were divided into 2 groups of 50 each. One group was given 4 doses of injection dexamethasone $6 \mathrm{mg}$ intramuscularly 12 hours apart while another group was given 2 doses of injection betamethasone $12 \mathrm{mg} 24$ hours apart. The neonates delivered were observed for respiratory distress syndrome, intraventricular haemorrhage, necrotising enterocolitis, low birth weight and neonatal mortality. Result: In our study the neonates who were given dexamethasone prenatally showed lesser evidences of respiratory distress syndrome (30\% vs $40 \%)$, intraventricular haemorrhage ( $2 \%$ vs $4 \%)$, necrotising colitis ( $2 \%$ vs $4 \%)$, low birth weight $(40 \%$ vs $50 \%)$ and neonatal deaths (4\% vs $8 \%)$ as compared to the neonates who received betamethasone before birth. Conclusion: Dexamethasone is superior over betamethasone in reducing adverse neonatal outcomes and more efficacious for preventing neonatal morbidities than betamethasone in pregnant women undergoing preterm deliveries.

Keywords: Dexamethasone, betamethasone, prematurity, respiratory distress syndrome, neonatal
\end{abstract}

outcomes.

Prematurity constitutes a serious complication in the field of obstetrics worldwide. The global incidence of preterm birth is around $10-15 \% .{ }^{1}$ Various untoward outcomes like respiratory distress syndrome, intra-ventricular haemorrhage, retinopathy of prematurity, necrotising enterocolitis, low birth weight, neonatal mortality are associated with premature birth. Antenatal corticosteroids are effectively used for acceleration of foetal lung maturation in preterm delivery. The two common antenatal corticosteroids recommended and widely used for accelerating fetal lung maturity in preterm labour are dexamethasone and betamethasone. According to ACOG, RCOG and WHO both dexamethasone and betamethasone are effective means of preventing prematurity related neonatal morbidities and mortality. ${ }^{1}$

Antenatal glucocorticosteroids have shown to accelerate development of type 1 and type 2 pneumocytes, which leads to structural and biochemical changes, thus improving both lung mechanics like lung volume, compliance in addition to gaseous exchange. ${ }^{2,3}$ Type 2 pneumocytes helps in

Received: $12^{\text {th }}$ July 2020, Peer review completed: $20^{\text {th }}$ August 2020, Accepted: $7^{\text {th }}$ September 2020.

Maji A, Ramani MV, Tiwari V. Dexamethasone versus betamethasone - a better modality for fetal lung maturity in preterm labour. The New Indian Journal of OBGYN. 2021; 8(1): 126-29. 
production of surfactant by providing surfactant proteins and enzymes required for synthesis of phospholipid. ${ }^{2,3}$ Antenatal corticosteroids also induce pulmonary beta-receptors, which result in release of surfactant and absorption of alveolar fluid. ${ }^{4}$ They also stimulates synthesis of fetal lung antioxidant enzymes. ${ }^{5}$ They play a significant role in upregulation in the gene expression for epithelial $\mathrm{Na}+$ channels which are required for absorption of lung fluid post birth. ${ }^{3}$

Aims and objectives: 1) Comparing efficacy of Table 3: Parity distribution

\begin{tabular}{lllll}
\hline Parity & $\begin{array}{l}\text { Group A }(\mathbf{N}=50) \\
\text { (Dexamethasone) }\end{array}$ & $\begin{array}{l}\text { Group B (N=50) } \\
\text { (Betamethasone) }\end{array}$ & $\begin{array}{l}\text { Chi-square } \\
\text { statistics }\end{array}$ & P - value \\
\hline Primi & $27(54 \%)$ & $26(52 \%)$ & 0.0401 & 0.841198 \\
Multi & $23(46 \%)$ & $24(48 \%)$ & & Not significant \\
\hline
\end{tabular}
dexamethasone and betamethasone for fetal lung maturity in preterm infants and 2) To study and compare incidence of other prematurity related complications in both groups.

\section{Materials and methods}

This was a hospital based prospective comparative study done in department of Obstetrics and Gynaecology at MVJ Medical College \& Research Hospital from $1^{\text {st }}$ May 2019 till $30^{\text {th }}$ April 2020 involving 100 consenting pregnant females presenting with preterm labour between the gestational age of 28 weeks to 36 weeks +6 days. Women with multiple pregnancies, preeclampsia, gestational diabetes mellitus (GDM), severe anaemia or those with pre-existing medical comorbidities like heart disease, epilepsy, etc were excluded from the study. A written and informed consent was taken from all included females. They were further divided into two groups of 50 each. One group was given 4 doses of injection dexamethasone $6 \mathrm{mg}$ intramuscularly 12 hours apart while another group was given 2 doses of injection betamethasone $12 \mathrm{mg} 24$ hours apart. The neonates delivered were observed for respiratory distress syndrome, intraventricular haemorrhage, necrotising enterocolitis, low birth weight and neonatal mortality.

All data of both group was tabulated and statistically analysed using suitable statistical tests. $\mathrm{P}$ value $<0.05$ was considered moderately significant and $\mathrm{P}$ value $<0.01$ as strongly significant. Odds ratio for neonatal outcome was assessed at 95\% confidence interval.

\section{Results}

Table no.1 shows comparison between the dexamethasone group and betamethasone group in terms of maternal age and gestational age at which baby was delivered. The difference between the two groups was statistically insignificant. In the table no. 2 , the difference in the number of early preterm and late preterm in the two groups was analysed and was found to be statistically insignificant. In the table no. 3, the variation in parity between the two groups was statistically insignificant.

Table - 4 shows the comparison of neonatal complications associated with preterm birth between dexamethasone group and betamethasone group. Respiratory distress syndrome was seen in $30 \%$ cases in group A as compared to $40 \%$ in group $B$ with odds ratio of 0.64 . The incidence of both intraventricular haemorrhage and necrotising colitis were $2 \%$ among the neonates in group $\mathrm{A}$ as compared to $4 \%$ of the neonates in group B. In group A, $40 \%$ babies were having low birth weight whereas, in group B, $50 \%$ babies were found to be having low birth weight with odds ratio of 0.67 . Neonatal mortality was evident in $4 \%$ neonates in group $\mathrm{A}$ as compared to $8 \%$ neonates in group $\mathrm{B}$ with odds ratio of 0.48 . The results suggest that neonates who received dexamethasone in utero are less likely to suffer from the complications of preterm births as compared to neonates who received prenatal betamethasone.

\begin{tabular}{llll} 
Table 4: Neonatal complications & & \\
\hline $\begin{array}{l}\text { Neonatal } \\
\text { outcome }\end{array}$ & $\begin{array}{l}\text { Group A (N=50) } \\
\text { (Dexamethasone) }\end{array}$ & $\begin{array}{l}\text { Group B (N=50) } \\
\text { (Betamethasone) }\end{array}$ & $\begin{array}{l}\text { Odds } \\
\text { ratio } \\
\text { (OR) }\end{array}$ \\
\hline $\begin{array}{l}\text { Respiratory } \\
\text { distress } \\
\text { syndrome }\end{array}$ & $15(30 \%)$ & $20(40 \%)$ & 0.64 \\
\hline $\begin{array}{l}\text { Intraventricular } \\
\text { hemorrhage }\end{array}$ & $1(2 \%)$ & $2(4 \%)$ & 0.49 \\
\hline $\begin{array}{l}\text { Necrotising } \\
\text { colitis }\end{array}$ & $1(2 \%)$ & $2(4 \%)$ & 0.49 \\
\hline $\begin{array}{l}\text { Low birth weight } \\
\text { Neonatal } \\
\text { mortality }\end{array}$ & $20(40 \%)$ & $25(50 \%)$ & 0.67 \\
\hline
\end{tabular}




\section{Discussion}

It is well known that administration of antenatal corticosteroids to women at high risk of preterm delivery reduces neonatal morbidity and mortality. However, previous studies provide conflicting results in respect to the choice of corticosteroid to be used for the same. The preference of one drug over the other depends on various factors including efficacy, availability and affordability. A thorough review of literature suggests very few studies done in India. Therefore, we aim to bring into light the best treatment modality applicable in an Indian scenario.

Our study observed similar baseline demographic characteristics in both groups in respect of maternal age (24.02 vs $23.96, p=0.464)$, gestational age (33.16 vs 32.6 , $\mathrm{p}=0.099)$ as well as parity $(\mathrm{p}=0.84)$. The incidence of intraventricular hemorrhage in preterm neonates was found to be less in group A as compared to group B ( $2 \%$ vs $4 \%$, OR 0.49 ). This observation was in congruence to previous large scale systemic cochrane reviews conducted by Brownfoot FC et al in 2008 and 2013 respectively. ${ }^{6,7}$ Similar results were further observed by Chhatrala JJ et al in 2015. This Indian study also reported a decreased in low birth weight infants $(40 \%$ vs $50 \%)$ in dexamethasone group. ${ }^{1}$ Comparable results were found in our study.

Dexamethasone group in our study evidenced a reduced neonatal mortality of $2 \%$ in comparison to $4 \%$ in betamethasone group. In addition to this, lower rates of necrotizing enterocolitis were observed in former as compared to latter ( $2 \%$ vs $4 \%$ ). This was in contrast to previous studies which reported no statistical difference in neonatal deaths in both groups. ${ }^{1,6-8}$

In our study, the development of respiratory distress syndrome (RDS) was lower in fetuses exposed to dexamethasone as compared to betamethasone $(30 \%$ vs 40\%). Brownfoot FC et al in 2013 and Crowther CA et al in 2019, however, reported no statistical difference in rates of RDS in both groups. ${ }^{7} 8$ In contrast to our results, Feldman et al in 2007 published their study where betamethasone group reported fewer number of RDS cases as compared to dexamethasone. ${ }^{9}$ The difference in our results as compared to international studies could be explained by the different salt of steroid being used. The above mentioned studies compared dexamethasone phosphate with combination of betamethasone phosphate + betamethasone acetate, also commercially known as 'celestone'. Manufacturing of celestone faced shortages in recent years and is not available in all countries including India. ${ }^{10}$ Due to nonavailability of this combination in our country; dexamethasone phosphate and betamethasone phosphate were used for analysis and comparison. Augusto FS et al in 2017 demonstrated combination of betamethasone acetate + phosphate to be superior to dexamethasone phosphate and betamethasone phosphate used individually. Hence explaining the contrasting results. ${ }^{11}$ There is a paucity of studies comparing dexamethasone phosphate with betamethasone phosphate.

Dexamethasone is more readily available due to its widespread usage for various medical indications and is moreover cheaper as compared to betamethasone. Despite finding similar efficacy of dexamethasone and betamethasone, the UN commission in 2013 recommended use of former over the latter. ${ }^{10}$ The WHO executive committee in its executive summary stated "while alternative steroids with similar efficacy were available, dexamethasone was considered the most appropriate product based in availability and cost". ${ }^{12}$

Danesh A et al in 2012 observed no significant differences in the maternal serum indictors of infection in either group. ${ }^{13}$ The 2013 cochrane review also found no statistically significant differences in maternal adverse effects between the two group. ${ }^{7}$. In 2019, ASTEROID trial by Crowther CA et al reported less pain at injection site in dexamethasone group. This large scale randomized trial also concluded that survival at 2 years without neurosensory disability was similar in both dexamethasone and betamethasone group. ${ }^{8}$ The evaluation of postnatal maternal adverse effects due to steroid administration (e.g. puerperal sepsis) as well as long term neonatal sequelae were beyond scope of this study. Further studies into long term maternal and neonatal outcomes are therefore recommended.

\section{Conclusion}

Dexamethasone is superior over betamethasone in reducing adverse neonatal outcomes and more efficacious for prevention neonatal morbidities than betamethasone in pregnant women with preterm deliveries.

\section{Conflict of interest: None. Disclaimer: Nil.}

\section{References}

1. Chhatrala J, Chawada R. Comparative study of dexamethasone and betamethasone for women at risk of preterm birth. International Journal of Reproduction, Contraception, Obstetrics and Gynecology. 2015; 4(4): 1000-3. 
2. Bonanno C, Wapner R. Antenatal corticosteroid treatment: what's happened since Drs Liggins and Howie?. American Journal of Obstetrics and Gynecology. 2009; 200(4): 448-57.

3. O'Brodovich HM. Immature epithelial $\mathrm{Na}+$ channel expression is one of the pathogenetic mechanisms leading to human neonatal respiratory distress syndrome. Proc Assoc Am Physicians. 1996; 108(5): 345-55.

4. Ballard P, Ballard R. Scientific basis and therapeutic regimens for use of antenatal glucocorticoids. American Journal of Obstetrics and Gynecology. 1995; 173(1): 254-62.

5. Grier D, Halliday H. Effects of Glucocorticoids on Fetal and Neonatal Lung Development. Treatments in Respiratory Medicine. 2004; 3(5): 295-306.

6. Brownfoot FC, Crowther CA, Middleton P. Different corticosteroids and regimens for accelerating fetal lung maturation for women at risk of preterm birth. Cochrane Database Syst Rev. 2008; 4: CD006764

7. Brownfoot F, Gagliardi D, Bain E, Middleton P, Crowther C. Different corticosteroids and regimens for accelerating fetal lung maturation for women at risk of preterm birth. Cochrane Database of Systematic Reviews. 2013; 8: CD006764.

8. Crowther C, Ashwood P, Andersen C, Middleton P, Tran T, Doyle L, et al. Maternal intramuscular dexamethasone versus betamethasone before preterm birth (ASTEROID): a multicentre, double-blind, randomised controlled trial. The Lancet Child \& Adolescent Health. 2019; 3(11): 769-80.
9. Feldman D, Carbone J, Belden L, Borgida A, Herson V. Betamethasone vs dexamethasone for the prevention of morbidity in very-low-birthweight neonates. American Journal of Obstetrics and Gynecology. 2007; 197(3): 284.e1-284.e4.

10. UN Commission / Born Too soon Care Antenatal Corticosteroids Working Group. Dexamethasone versus betamethasone as an antenatal corticosteroid (ACS) [Internet]. 2013. Available from: http:/www. healthynewbornnetwork.org/sites/default/files/resources/ ACS Beta vs Dexa 130820.pdf

11. Schmidt A, Kemp M, Kannan P, Kramer B, Newnham J, Kallapur S, et al. Antenatal dexamethasone vs. betamethasone dosing for lung maturation in fetal sheep. Pediatric Research. 2017; 81(3): 496-503.

12. Expert Committee on Selection and Use of Essential Medicines. Executive summary [Internet]. 2013. Available from: https://www.who.int/ medicines/ EMP_Website_notice_EML_July2013.pdf

13. Danesh A, Janghorbani M, Khalatbari S. Effects of antenatal corticosteroids on maternal serum indicators of infection in women at risk for preterm delivery: A randomized trial comparing betamethasone and dexamethasone. J Res Med Sci. 2012;17(10):911-917.

\footnotetext{
Aritra Maji ${ }^{1}$, Manisha V Ramani ${ }^{2}$, Vidushi Tiwari ${ }^{3}$

${ }^{1}$ Assistant Professor, MVJ Medical College \& Research Hospital, Bengaluru, India; ${ }^{2}$ Assistant Professor, MVJ Medical College \& Research Hospital, Bengaluru, India;

${ }^{3}$ Junior Resident, MVJ Medical College \& Research Hospital, Bengaluru, India.
} 